\title{
Resumen
}

Según Levy-Leboyer (1997; 54) las competencias son "repertorios de comportamientos que algunas personas dominan mejor que otras lo que las hace eficaces en una situación determinada". Estos comportamientos son observables en la realidad cotidiana del trabajo e igualmente en situaciones de test. Dentro de toda organización pública, los funcionarios tienen la posibilidad de desarrollar una Carrera Funcionaria, concepto que está vinculado a una serie de etapas por las cuales un trabajador/a puede transitar. Por esto, la investigación tiene por objeto analizar las competencias laborales, reclutamiento y carrera funcionaria, que existen dentro de los servicios públicos, en la Quinta Región. Concluyendo que se debe hacer urgentemente un cambio en el Estatuto Administrativo, modificarlo de manera tal que los ascensos sean más rápidos, que las calificaciones sean especificas al trabajo realizado, que las capacitaciones sean para todos los funcionarios y también en temáticas que le sirvan para una futura postulación y, finalmente, que las Universidades estatales logren tener una mayor autonomía de la que tienen, en sus procesos administrativos y económicos.

Palabras claves: Competencias Laborales, Reclutamiento, Administración del Personal, Servicios Públicos, Carrera Funcionaria, Estatuto Administrativo.

\section{ANÁLISIS DE LAS COMPETENCIAS LABORALES, RECLUTAMIENTO Y CARRERA FUNCIONARIA EN LOS SERVICIOS PÚBLICOS DE LA QUINTA REGIÓN.}

\section{ANALYSIS OF THE LABOR COMPETENCES, RECRUITMENT AND FUNCTIONARY CAREER IN PUBLIC SERVICES OF THE V REGION.}

\section{Mónica Alejandra Riffo Rosas ${ }^{1}$}

\section{Abstract}

According to Levy-Leboyer $(1997 ; 54)$ the competences are "behavioral repertoires which some people control better than others and which makes them efficient in a particular situation". These behaviors can be observed in people's everyday working life as well as in evaluating situations. In all public organizations, the functionaries have the possibility of developing a functionary career which is related to a series of stages that a worker can go through during his/her working life. Due to this, the investigation aims to analyze the labor competences, recruitment and functionary career that exist within public services of the $\mathrm{V}$ region. And concluding that an urgent change must be done in the Administrative Ordinance; this means, modifying it in such a way that promotions are quicker, evaluations are carried out according to the work done, professional training is given to all the functionaries and based on topics which are useful for a future application, and finally, that state universities can have a greater autonomy than the one they have in their administrative and economic processes.

Key Words: Labor Competences, Recruitment, Personnel Administration, Public Services, Functionary Career, Administrative Ordinance.

\footnotetext{
${ }_{1}$ Alumna Tesista de la Carrera de Auditoría de la Universidad de Valparaíso, teniendo como profesor guía
} a la profesora Dra. Karime Chahuán Jiménez. 


\section{INTRODUCCIÓN.}

\section{ADMINISTRACIÓN DEL RECURSO HUMANO (PERSONAL)}

Según Chiavenato (2004) la administración constituye el modo de lograr que las cosas se hagan de la mejor manera posible. Comprende la coordinación de recursos humanos y materiales para conseguir los objetivos. Por ello los cuatro ámbitos básicos de trabajo de la administración son:

\section{1.- Logro de objetivos}

2.- Por medio de las personas

3.-.Utilización de tecnología

4.- En una organización

Dentro de una organización, existe la administración del personal, que se ocupe de las políticas y prácticas requeridas para llevar a cabo los aspectos relativos a las personas 0 al puesto que ocupa cada una de éstas. (Dessler, 2001)

A nivel administrativo, se menciona los siguientes aspectos:

- $\quad$ Realizar Análisis de los puestos. (determinar la naturaleza del trabajo de cada empleado)

Planificar las necesidades laborales y reclutar a candidatos para esos puestos.

- Seleccionar a los candidatos para los puestos.

- Orientar y capacitar a los nuevos empleados.

- $\quad$ Administrar los sueldos y salarios. (determinar cómo se compensará a los empleados)

- $\quad$ Brindar incentivos y prestaciones.

- Evaluar el desempeño.

- $\quad$ Comunicar (entrevistar, asesorar, disciplinar)

- Capacitar y desarrollar.

- Fomentar el compromiso con los empleados. (Dessler, 2001)

A nivel gerencial, se mencionan los siguientes aspectos:

- Igualdad de oportunidades y la acción afirmativa.

- $\quad$ La salud y la seguridad de los empleados.

- $\quad$ Las querellas y relaciones laborales.

(Dessler, 2001)

A través de la administración de personal, se puede lograr una competitividad organizacional, desarrollándose a través de cinco procesos básicos, lo cuales son: Provisión, Aplicación, Mantenimiento, Desarrollo, Seguimiento y Control del Personal. (Chiavenato, 2004)
Cuadro 1:

Cinco procesos básicos en la Administración de Personal.

\begin{tabular}{|c|l|l|}
\hline Proceso & \multicolumn{1}{|c|}{ Objetivo } & \multicolumn{1}{|c|}{ Actividades Comprendidas } \\
\hline Provisión & $\begin{array}{l}\text { Quién irá a trabajar } \\
\text { en la organización }\end{array}$ & $\begin{array}{l}\text { - Investigación de mercado de recursos } \\
\text { humanos } \\
\text { : Reclutamiento de personal } \\
\text { Selección de personal }\end{array}$ \\
\hline Aplicación & $\begin{array}{l}\text { Qué harán las } \\
\text { personas en la } \\
\text { organización }\end{array}$ & $\begin{array}{l}\text { : Integración de personas } \\
\text { M Diseño de cargos } \\
\text { Descripción y análisis de los cargos }\end{array}$ \\
\hline Evaluación del desempeño
\end{tabular}

Fuente: Elaboración Propia de acuerdo a Chiavenato, 2004

La administración de recursos humanos refieren a aspectos internos de la organización (enfoque endógeno) y aspectos externos 0 ambientales (enfoque exógeno). Algunas de éstas se aplican directamente a las personas, que son los sujetos de su aplicación y otras indirectamente, a través de los cargos que ocupan 0 bien mediante planes o programas globales 0 específicos. (Chiavenato, 2004)

Figura 1: Técnicas de Administración de Recursos Humanos aplicadas directamente a las personas 0 indirectamente a través de los cargos ocupados 0 de los planes globales 0 específicos.

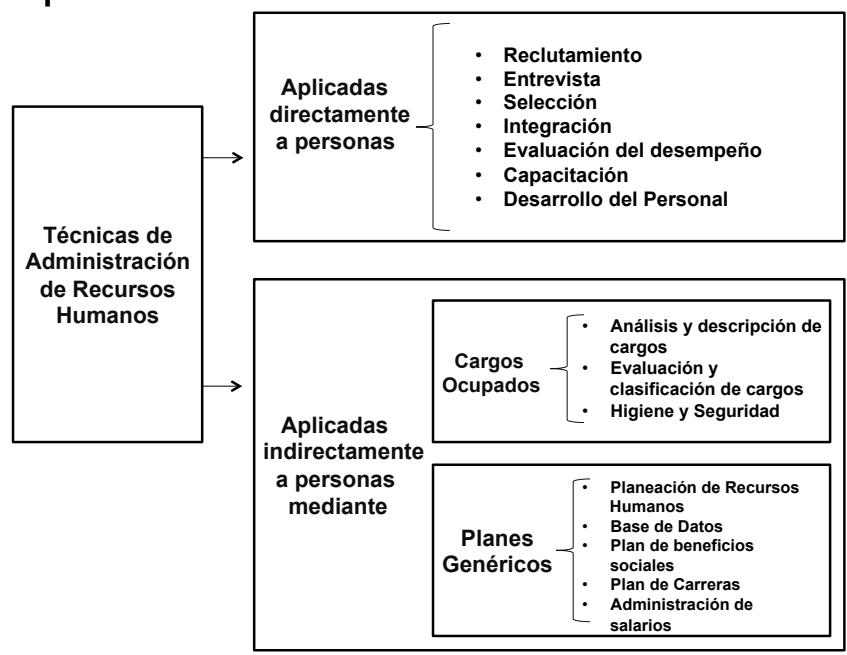

Fuente: Elaboración Propia en base a Chiavenato, 2004 


\section{RECLUTAMIENTO}

Las personas y organizaciones se encuentran en un desarrollo continuo e interactivo en éste, existe una relación y atracción mutua. Cada organización escoge a las personas que desea como empleados, así como cada persona elige la organización a la cual quiere pertenecer. Esta elección recíproca depende de diversos factores y circunstancias, es por esto que el reclutamiento cumple un papel fundamental dentro de este proceso. (Chiavenato, 2004)

"El Reclutamiento corresponde al proceso mediante el cual la organización atrae candidatos para abastecer su proceso selectivo". (Chiavenato, 2004; 95)

\section{TIPOS DE RECLUTAMIENTO}

El reclutamiento puede ser interno, el cual es aplicado a los candidatos que trabajan en la organización, o bien externo el cual se dirige a los candidatos que están en el mercado de recursos humanos. (Chiavenato 2004)

\section{Figura 2: Reclutamiento Interno y Externo.}

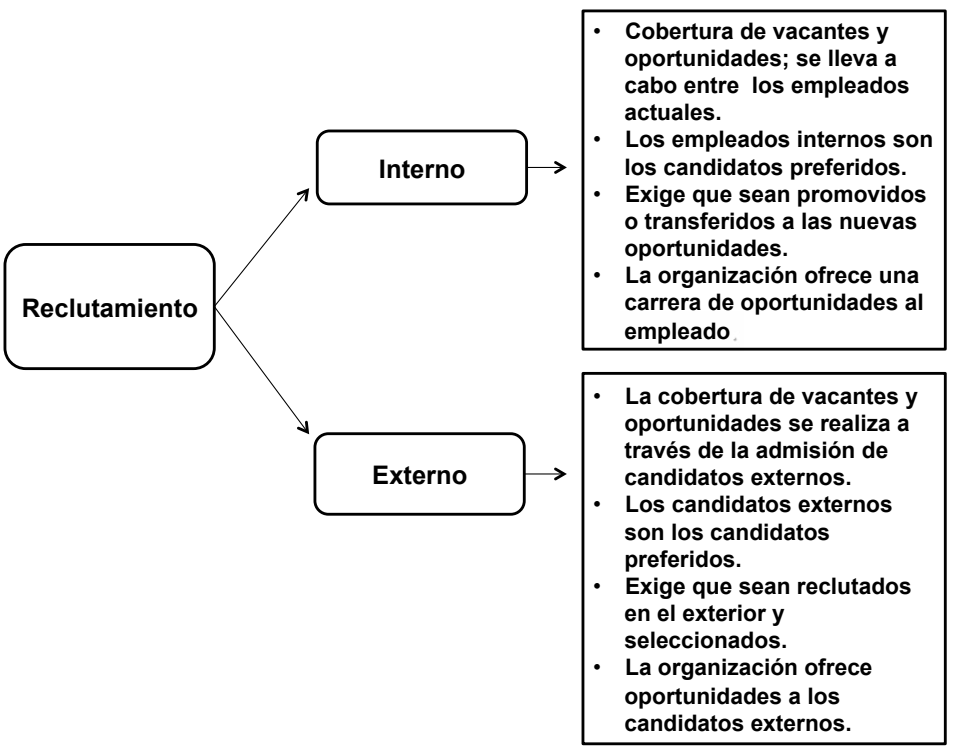

Fuente: Elaboración Propia de acuerdo a Chiavenato, 2004

\section{COMPETENCIAS LABORALES}

Levy-Leboyer (1997; 54), define las competencias laborales como "repertorios de comportamientos que algunas personas dominan mejor que otras lo que las hace eficaces en una situación determinada. Estos comportamientos son observables en la realidad cotidiana del trabajo e igualmente en situaciones de test. Ponen en práctica, de forma integrada aptitudes, rasgos de personalidad y conocimientos adquiridos"

\section{CLASIFICACIÓN DE LAS COMPETENCIAS}

Para Spencer y Spencer de acuerdo a Alles (2010) son cinco los principales tipos de competencias:

\section{Cuadro 2: Tipos de Competencias.}

\begin{tabular}{|l|}
\hline Motivación \\
\hline $\begin{array}{l}\text { Los intereses que una persona considera o desea consistentemente. Las } \\
\text { motivaciones "dirigen, conllevan y seleccionan" el comportamiento hacia } \\
\text { ciertas acciones u objetivos y lo alejan de otros. }\end{array}$ \\
\hline Caracteristicas \\
\hline Características físicas y respuestas consistentes a situaciones o información. \\
\hline Concepto propio o concepto de uno mismo \\
\hline Las actitudes, valores o imagen propia de una persona. \\
\hline Conocimiento \\
\hline La información que una persona posee sobre áreas específicas. \\
\hline Habilidad \\
\hline La capacidad de desempeñar cierta tarea fisica o mental. \\
\hline
\end{tabular}

Fuente: Elaboración Propia de acuerdo a Alles, 2010

Muchas organizaciones seleccionan en base a conocimientos y habilidades, y asumen que los nuevos empleados poseen la motivación fundamental y las características necesarias, 0 que estas competencias se pueden infundir mediante un buen management.

En los puestos complejos, las competencias son más importantes que las habilidades relacionadas con la tarea, inteligencia o las credenciales, para predecir un desempeño superior. Esto se debe al "efecto restringido de rango". 
Figura 3: Clasificación de las competencias según su dificultad de detección.

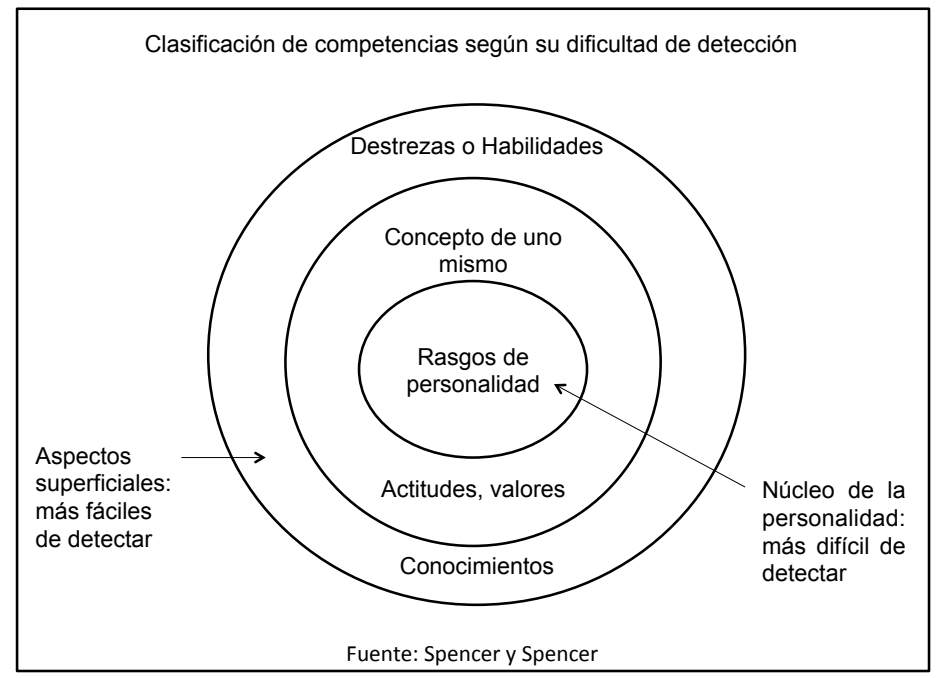

Fuente: Elaboración Propia en base a Alles, (2010)

Por otro lado, Alles (2010) plantea diferentes competencias las cuales denomina supra competencias:

\section{Cuadro 3: Supra-Competencias}

\begin{tabular}{|l|l|}
\hline \multicolumn{1}{|c|}{ Supra-Competencias } & \multicolumn{1}{c|}{ Caracteristicas } \\
\hline Intelectuales & $\begin{array}{l}\text { - Perspectiva estratégica } \\
\text { - Análisis y sentido común } \\
\text { - Planificación y organización }\end{array}$ \\
\hline Interpersonales & $\begin{array}{l}\text { - Dirigir colaboradores } \\
\text { - Persuasión } \\
\text { - Decisión } \\
\text { - Sensibilidad interpersonal } \\
\text { - Comunicación oral }\end{array}$ \\
\hline Adaptabilidad & \begin{tabular}{l} 
- Adaptación al medio \\
\hline Orientación a Resultados
\end{tabular} \\
\hline
\end{tabular}

Fuente: Elaboración Propia en base a Alles, (2010)

\section{GESTION DE LAS COMPETENCIAS LABORALES}

Dentro de la gestión de competencias, se habla de dos tipos de competencias:

1.- Competencias diferenciadoras, las cuales permiten explicar las diferencias entre los distintos empleados de la organización.

2.- Competencias umbral o esenciales, que son las que se consideran necesarias para lograr unos resultados mínimos que sean aceptables.

Figura 4: Tipos de competencias a través de la Gestión de Competencias.

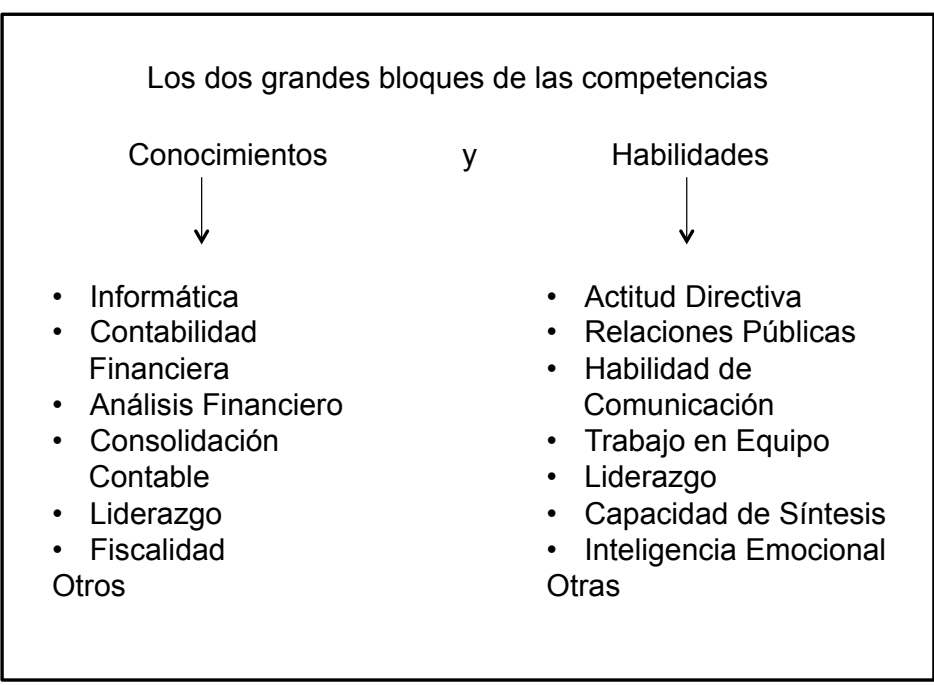

Fuente: De acuerdo a Dolan (2003)

\section{CARRERA PROFESIONAL}

"Es la sucesión de actividades laborales y puestos de trabajo desempeñados por una persona a lo largo de su vida, así como las actitudes y reacciones asociadas que experimenta." (Simon L Dolan, 2003; 145)

De acuerdo a Douglas T. Hall existen cuatro diferentes etapas donde transita la persona, éstas son:

- $\quad$ Exploración: La persona identifica sus preferencias, interés y oportunidades.

- $\quad$ Avance: La persona juega papeles con relevancia en la organización

- Mantenimiento: Se optimiza las capacidades y conocimientos

- $\quad$ Declive: No mantiene el nivel con el paso del tiempo. 


\section{Figura 5: Etapas de la Carrera de D.T. Hall}

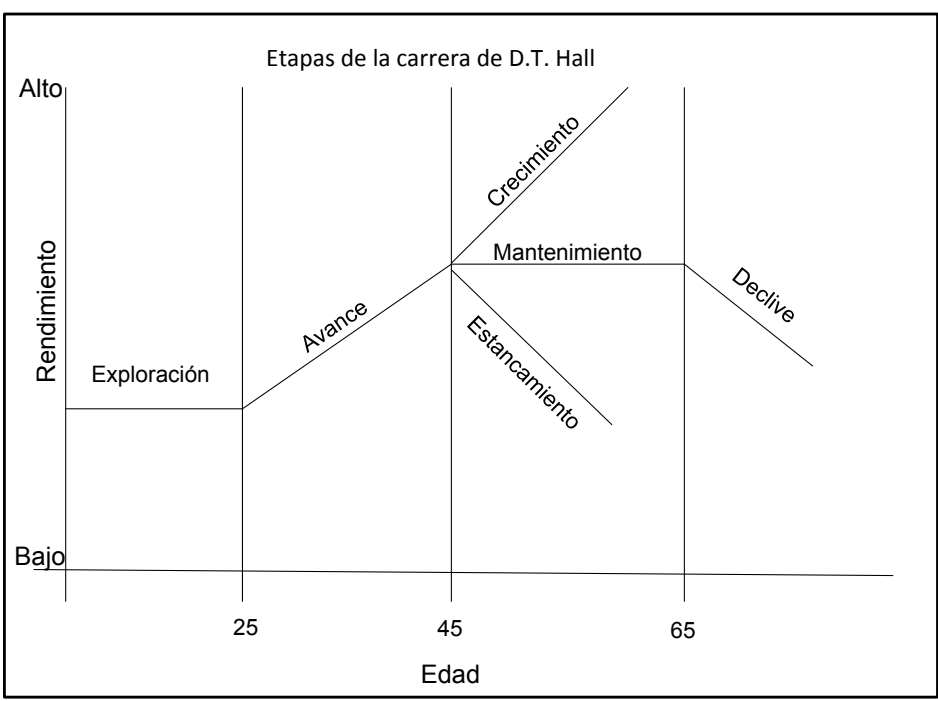

Fuente: De acuerdo a Dolan (2003)

\section{CARRERA FUNCIONARIA}

De acuerdo a la Ley 18.834 "Estatuto Administrativo", en su artículo tercero, define a la carrera funcionaria como "Un sistema integral de regulación del empleo público, aplicable al personal titular de planta, fundado en principios jerárquicos, profesionales y técnicos, que garantiza la igualdad de oportunidades para el ingreso, la dignidad de la función pública, la capacitación y el ascenso, la estabilidad en el empleo, y la objetividad en las calificaciones en función del mérito y de la antigüedad."

\section{INGRESO (CONCURSO PÚBLICO)}

Artículo 17.- El ingreso a los cargos, de carrera en calidad de titular se hará por concurso público y procederá en el último grado de la planta respectiva, salvo que existan vacantes de grados superiores a éste que no hubieren podido proveerse mediante promociones. Todas las personas que cumplan con los requisitos correspondientes tendrán el derecho a postular en igualdad de condiciones. (DFL 29, 2004)

Artículo 18.- El concurso consistirá en un procedimiento técnico y objetivo que se utilizará para seleccionar el personal que se propondrá a la autoridad facultada para hacer el nombramiento, debiéndose evaluar los antecedentes que presenten los postulantes y las pruebas que hubieren rendido, si así se exigiere, de acuerdo a las características de los cargos que se van a proveer. (DFL 29, 2004)

Artículo 20.- La autoridad facultada para hacer el nombramiento publicará un aviso con las bases del concurso en el Diario Oficial, Ios días $1^{\circ} 015$ de cada mes 0 el primer día hábil siguiente si aquellos fueren feriado, sin perjuicio de las demás medidas de difusión que estime conveniente adoptar. Entre la publicación en el Diario Oficial y la fecha de presentación de antecedentes no podrá mediar un lapso inferior a ocho días. (DFL 29, 2004)

El aviso deberá contener, a lo menos la identificación de la institución solicitante, las características del cargo, los requisitos para su desempeño, la individualización de los antecedentes requeridos, la fecha y lugar de recepción de éstos, las fechas y lugar en que se tomarán las pruebas de oposición, si procediere, y el día en que se resolverá el concurso. (DFL 29, 2004)

Artículo 21.- El concurso podrá ser declarado total o parcialmente desierto sólo por falta de postulantes idóneos, entendiéndose que existe tal circunstancia, cuando ninguno alcance el puntaje mínimo definido para el respectivo concurso. (DFL 29, 2004)

\section{PROMOCIÓN Y ASCENSO}

Artículo 53. - La promoción se efectuará por concurso interno en las plantas de directivos de carrera, profesionales, fiscalizadores y técnicos y por ascenso en el respectivo escalafón en las plantas de administrativos y de auxiliares, 0 en las equivalentes a las antes enumeradas. (DFL 29, 2004)

Las bases de estos concursos deberán considerar sólo los siguientes factores:

\section{Tabla 1: Factores de ponderación}

\begin{tabular}{|c|c|}
\hline Factores & Ponderación \\
\hline Capacitación pertinente & $25 \%$ \\
\hline Evaluación del desempeño & $25 \%$ \\
\hline Experiencia calificada & $25 \%$ \\
\hline Aptitud para el cargo & $25 \%$ \\
\hline
\end{tabular}

Fuente: Elaboración propia de acuerdo a Decreto Fuerza de Ley № 29, 2004

La promoción, por concurso interno, regirá a partir de la fecha en que quede totalmente tramitado el acto administrativo que la dispone. (DFL 29, 2004)

Artículo 54.- El ascenso es el derecho de un funcionario de acceder a un cargo vacante de grado superior en la línea jerárquica de la respectiva planta, sujetándose estrictamente al escalafón, sin perjuicio de lo dispuesto en el artículo 56. (DFL 29, 2004)

Artículo 56.- Un funcionario de la Planta de Auxiliares tendrá derecho 
a ascender a un cargo de la Planta de Administrativos, gozando de preferencia respecto de los funcionarios de ésta, cuando se encuentre en el tope de su planta, reúna los requisitos para ocupar el cargo y tenga un mayor puntaje en el escalafón que los funcionarios de la planta a la cual accede.

Este derecho corresponderá al funcionario que, cumpliendo las mismas exigencias del inciso anterior, ocupe el siguiente lugar en el escalafón, en el mismo grado, si el primer funcionario renunciare a él. (DFL 29 2004)

\section{GRADO}

Artículo $9^{\circ}$.- Todo cargo público necesariamente deberá tener asignado un grado de acuerdo con la importancia de la función que se desempeñe y, en consecuencia, le corresponderá el sueldo de ese grado y las demás remuneraciones a que tenga derecho el funcionario. (DFL 29, 2004)

De acuerdo al DFL $N^{\circ} 4$, los escalafones tienen los siguientes grados:

\section{- Estamento Profesional}

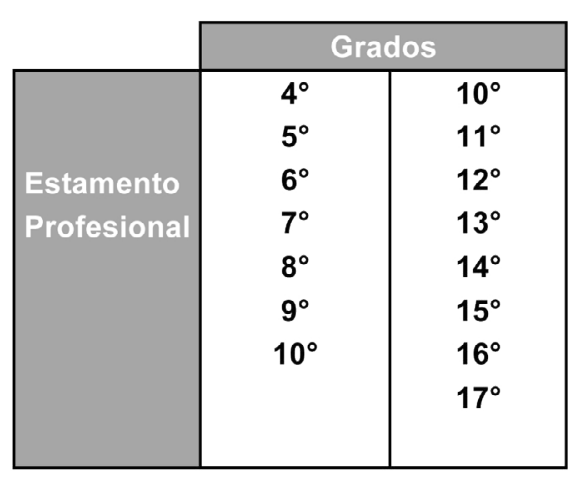

Fuente: DFL 4

\section{- Estamento Técnico}

\begin{tabular}{|c|c|c|}
\cline { 2 - 3 } \multicolumn{1}{c|}{} & \multicolumn{2}{c|}{ Grados } \\
\hline \multirow{3}{*}{ Estamento } & $13^{\circ}$ & $18^{\circ}$ \\
Técnico & $14^{\circ}$ & $19^{\circ}$ \\
& $15^{\circ}$ & $20^{\circ}$ \\
& $16^{\circ}$ & $21^{\circ}$ \\
& $17^{\circ}$ & $22^{\circ}$ \\
\hline
\end{tabular}

Fuente: DFL 4
- $\quad$ Estamento Administrativo

\begin{tabular}{|c|c|c|}
\cline { 2 - 3 } \multicolumn{1}{c|}{} & \multicolumn{2}{c|}{ Grados } \\
\hline \multirow{4}{*}{ Estamento } & $12^{\circ}$ & $17^{\circ}$ \\
& $13^{\circ}$ & $18^{\circ}$ \\
Administrativo & $14^{\circ}$ & $19^{\circ}$ \\
& $15^{\circ}$ & $20^{\circ}$ \\
& $16^{\circ}$ & $21^{\circ}$ \\
& $17^{\circ}$ & $22^{\circ}$ \\
\hline
\end{tabular}

Fuente: DFL 4

- $\quad$ Estamento Auxiliares

\begin{tabular}{|c|c|c|}
\cline { 2 - 3 } \multicolumn{1}{c|}{} & \multicolumn{2}{c|}{ Grados } \\
\hline \multirow{3}{*}{ Estamento } & $13^{\circ}$ & $18^{\circ}$ \\
Técnico & $14^{\circ}$ & $19^{\circ}$ \\
& $15^{\circ}$ & $20^{\circ}$ \\
& $16^{\circ}$ & $21^{\circ}$ \\
& $17^{\circ}$ & $22^{\circ}$ \\
\hline
\end{tabular}

Fuente: DFL 4 


\section{CALIFICACIONES}

Artículo 32.- El sistema de calificación tendrá por objeto evaluar el desempeño y las aptitudes de cada funcionario, atendidas las exigencias y características de su cargo, y servirá de base para la promoción, los estímulos y la eliminación del servicio. (DFL 29, 2004)

Artículo 33.- Todos los funcionarios, incluido el personal a contrata, deben ser calificados anualmente, en alguna de las siguientes listas: Lista № 1, de Distinción; Lista № 2, Buena; Lista № 3, Condicional; Lista № 4, de Eliminación. El Jefe Superior de la institución será personalmente responsable del cumplimiento de este deber. (DFL 29, 2004)

Artículo 35.- La calificación se hará por la Junta Calificadora. En cada institución existirán Juntas Calificadoras Regionales que harán las calificaciones de sus funcionarios cuando el número de éstos, en la región, sea igual o superior a quince. (DFL 29, 2004)

Artículo 38.- La calificación evaluará los doce meses de desempeño funcionario comprendidos entre el $1^{\circ}$ de septiembre de un año y el 31 de agosto del año siguiente. (DFL 29, 2004)

Con todo, los reglamentos especiales propios de cada institución podrán establecer otras fechas de inicio y término del periodo anual de desempeño a calificar. (DFL 29, 2004)

Artículo 41.- La Junta Calificadora adoptará sus resoluciones teniendo en consideración, necesariamente, la precalificación del funcionario hecha por su Jefe Directo, la que estará constituida por los conceptos, notas y antecedentes que éste deberá proporcionar por escrito. Entre los antecedentes, se considerarán las anotaciones de mérito 0 de demérito que se hayan efectuado dentro del período anual de calificaciones, en la hoja de vida que llevará la oficina encargada del personal para cada funcionario. (DFL 29, 2004)

Los jefes serán responsables de las precalificaciones que efectúen, como asimismo, de la calificación en la situación prevista en el inciso segundo del artículo 29. La forma en que lleven a cabo este proceso deberá considerarse para los efectos de su propia calificación. (DFL 29, 2004)

De acuerdo al Decreto 1.825, en el título dos, párrafo segundo. Los factores de calificación se clasifican como sigue:

Artículo 14.- La calificación evaluará los factores y sub-factores que se señalarán, por medio de notas que tendrán los siguientes valores y conceptos:
Tabla 2: Factores y sub-factores

\begin{tabular}{|c|c|}
\hline Factores & Sub-Factores \\
\hline $\begin{array}{l}\text { Rendimiento } \\
\text { Mide el trabajo ejecutado } \\
\text { durante el periodo, en } \\
\text { relación a las tareas } \\
\text { encomendadas. }\end{array}$ & $\begin{array}{l}\text { a) Cumplimiento de la labor realizada: mide la } \\
\text { realización de los trabajos asignados y la rapidez y } \\
\text { oportunidad en su ejecución. } \\
\text { b) Calidad de la labor realizada: evalúa las } \\
\text { caracteristicas de la labor cumplida y la ausencia de } \\
\text { errores en el trabajo y la habilidad en su ejecución. }\end{array}$ \\
\hline $\begin{array}{l}\text { Condiciones Personales } \\
\text { Evalúa la actitud del } \\
\text { funcionario en su vinculación } \\
\text { con los demás. }\end{array}$ & $\begin{array}{l}\text { a) Interés por el trabajo que realiza: mide el deseo } \\
\text { del funcionario de perfeccionarse en el } \\
\text { cumplimiento de sus obligaciones, de proponer la } \\
\text { realización de actividades y de soluciones ante los } \\
\text { problemas que se presenten y de proponer } \\
\text { objetivos o procedimientos nuevos para la mejor } \\
\text { realización del trabajo asignado. } \\
\text { b) Capacidad para realizar trabajos en equipo: } \\
\text { mide la facilidad de integración del funcionario en } \\
\text { equipos de trabajo, así como la colaboración eficaz } \\
\text { que éste presta cuando se requiere que trabaje con } \\
\text { grupos de personas. }\end{array}$ \\
\hline $\begin{array}{l}\text { Comportamiento } \\
\text { Funcionario } \\
\text { Evalúa la conducta del } \\
\text { funcionario en el cumplimiento } \\
\text { de sus obligaciones. }\end{array}$ & $\begin{array}{l}\text { a) Cumplimiento de normas e instrucciones: mide } \\
\text { el respeto a los reglamentos e instrucciones de la } \\
\text { institución y a los demás deberes estatutarios. } \\
\text { b) Asistencia y puntualidad: mide la presencia o } \\
\text { ausencia del funcionario en el lugar de trabajo y la } \\
\text { exactitud en el cumplimiento de la jornada laboral. }\end{array}$ \\
\hline
\end{tabular}

Fuente: Elaboración propia de acuerdo a Decreto № 1825, 1998. 


\section{Tabla 3: Calificaciones}

\begin{tabular}{|c|c|l|}
\hline Nota & Calificación & \multicolumn{1}{|c|}{ Conceptos } \\
\hline 9-10 & Óptimo & $\begin{array}{l}\text { Generalmente su desempeño excede los } \\
\text { requerimientos que exige el desarrollo del } \\
\text { cargo. }\end{array}$ \\
\hline 7-8 & Bueno & $\begin{array}{l}\text { Su desempeño satisface completamente los } \\
\text { requerimientos exigidos para el desarrollo del } \\
\text { cargo. }\end{array}$ \\
\hline 3-4 & Satisfactorio & $\begin{array}{l}\text { Su desempeño generalmente satisface los } \\
\text { requerimientos que exige el desarrollo del } \\
\text { cargo. }\end{array}$ \\
\hline Insuficiente & $\begin{array}{l}\text { Su desempeño es inferior a los requerimientos } \\
\text { que exige el desarrollo del cargo. }\end{array}$ \\
\hline Deficiente & $\begin{array}{l}\text { No cumple con los requerimientos que exige el } \\
\text { desarrollo del cargo }\end{array}$ \\
\hline
\end{tabular}

Fuente: Elaboración propia, de acuerdo a Decreto № 1825, 1998.

\section{CAPACITACIÓN}

Artículo 26.- Se entenderá por capacitación el conjunto de actividades permanentes, organizadas y sistemáticas destinadas a que los funcionarios desarrollen, complementen, perfeccionen 0 actualicen los conocimientos y destrezas necesarios para el eficiente desempeño de sus cargos 0 aptitudes funcionarias. (DFL 29, 2004)

Artículo 27.- Existirán los siguientes tipos de capacitación, que tendrán el orden de preferencia que a continuación se señala:

a) La capacitación para la promoción que corresponde a aquella que habilita a los funcionarios para asumir cargos superiores. La selección de los postulantes se hará estrictamente de acuerdo al escalafón. No obstante, será voluntaria y, por ende, la negativa a participar en los respectivos cursos no influirá en la calificación del funcionario. (DFL 29, 2004)

b) La capacitación de perfeccionamiento, que tiene por objeto mejorar el desempeño del funcionario en el cargo que ocupa. La selección del personal que se capacitará, se realizará mediante concurso. (DFL 29, 2004)

c) La capacitación voluntaria, que corresponde a aquella de interés para la institución, y que no está ligada a un cargo determinado, ni es habilitante para el ascenso. El jefe superior de la institución, el Secretario Regional Ministerial 0 el Director Regional de servicios nacionales desconcentrados, según corresponda, determinará su procedencia y en tal caso seleccionará a los interesados, mediante concurso, evaluando los méritos de los candidatos. (DFL 29, 2004)

Artículo 28.- Los estudios de educación básica, media o superior y los cursos de post-grado conducentes a la obtención de un grado académico, no se considerarán actividades de capacitación y de responsabilidad de la institución.

Artículo 29.- Las instituciones deberán distribuir los fondos que sean asignados en programas de capacitación nacionales, regionales 0 locales, de acuerdo con las necesidades y características de las correspondientes funciones y siguiendo el orden de preferencia señalado en el artículo 27. (DFL 29, 2004)

Artículo 31.- Los funcionarios seleccionados para seguir cursos de capacitación tendrán la obligación de asistir a éstos, desde el momento en que hayan sido seleccionados, y los resultados obtenidos deberán considerarse en sus calificaciones. (DFL 29, 2004)

\section{METODOLOGÍA}

La metodología de la investigación es cualitativa con un alcance comprehensivo.

El objeto de estudio se concentra en dos instituciones públicas de la Quinta Región, las cuales son: Universidad de Valparaíso y Ministerio de Educación (Regional)

Para tomar conocimiento de la realidad se entrevistar a:

- Secretario Regional (Mineduc) ; Secretario General (Universidad de Valparaíso)

- $\quad$ Encargado de Administración y RR.HH (Mineduc); Jefe Departamento RR.HH (Universidad de Valparaíso)

- $\quad$ Auditoría Interna (Mineduc); Contralor General (Universidad de Valparaíso)

- $\quad$ Dirigente Andime ( Mineduc); Dirigente AFA ( Universidad de Valparaíso)

De la evaluación y respuestas se obtienen las siguientes categorías y sub categorías: 


\section{Universidad de Valparaíso}

\begin{tabular}{|c|c|c|}
\hline Categoria & Sub-Categoria & Sub-Sub-Categorias \\
\hline $\begin{array}{l}\text { A: Administración } \\
\text { de Personal }\end{array}$ & $\begin{array}{l}\text { A1: Desarrollo del personal } \\
\text { A2: Definición de cargos o } \\
\text { perfiles } \\
\text { A3: Incentivos al personal } \\
\text { A4: Evaluación de los } \\
\text { desempeños }\end{array}$ & $\begin{array}{l}\text { A1-1-1: Tipos de desarrollo } \\
\text { A2-1-1: Evaluación de perfiles } \\
\text { A3-1-2: Recompensas } \\
\text { A4-1-2: Capacidad de evaluación } \\
\text { honesta }\end{array}$ \\
\hline B: Reclutamiento & $\begin{array}{l}\text { B1: Proceso de ingreso } \\
\text { B2: Procedimiento } \\
\text { B3: Inducción }\end{array}$ & $\begin{array}{l}\text { B1-1-3:Bases de concurso } \\
\text { B2-1-3:Tipos de concurso } \\
\text { B3-1-2: Garantías del concurso } \\
\text { B2-1-1:Procedimiento en el } \\
\text { concurso público }\end{array}$ \\
\hline $\begin{array}{l}\text { C: Competencias } \\
\text { Laborales }\end{array}$ & $\begin{array}{l}\text { C1: Definición } \\
\text { C2: Reconocimiento de } \\
\text { Competencias } \\
\text { C3: Determinación de las } \\
\text { competencias } \\
\text { C4: Gestión de las } \\
\text { competencias. }\end{array}$ & $\begin{array}{l}\text { C1-1-2:Competencias } \\
\text { Técnicas y Blandas } \\
\text { C1-2-3: Modelo de Competencias } \\
\text { C2-1-2: A nivel de Profesión } \\
\text { C2-2-3: A nivel Directivo } \\
\text { C3-1-1: Competencias según } \\
\text { cargos } \\
\text { C3-2-3: Competencias a } \\
\text { contemplar. }\end{array}$ \\
\hline $\begin{array}{l}\text { D: Carrera } \\
\text { Funcionaria }\end{array}$ & $\begin{array}{l}\text { D1: Definición } \\
\text { D2: Aplicación } \\
\text { D3: Ingreso } \\
\text { D4: Capacitación } \\
\text { D5: Calificaciones } \\
\text { D6: Ascenso } \\
\text { D7: Carrera Académica }\end{array}$ & $\begin{array}{l}\text { D1-1-1: Promoción } \\
\text { D2-2-3: Objetivo } \\
\text { D2-1-4:Problemas a la aplicación } \\
\text { D3-1: Medio de ingreso } \\
\text { D4-1: Beneficiados } \\
\text { D4-1-4: Regulación } \\
\text { D5-1-1: Conceptos de evaluación } \\
\text { D5-1-1: Puntuación } \\
\text { D5-1-4: Junta calificadora } \\
\text { D6-1-3: Mecanismo de nivelación } \\
\text { D7-1-1: Jerarquías Académicas } \\
\text { D7-2-4: Ascenso Académico }\end{array}$ \\
\hline
\end{tabular}

Fuente: Elaboración Propia
DISCUSIÓN DE RESULTADOS

De acuerdo a lo planteado por Dessler (2001) las políticas y las prácticas que se requiere llevar a cabo en relación a las personas son las siguientes:

\section{Tabla 5: Políticas y Prácticas en relación a las personas.}

\begin{tabular}{|c|c|c|c|}
\hline Concepto & Universidad de Valparaiso & & Discusión del Resultado \\
\hline $\begin{array}{l}\text { Orientar y } \\
\text { capacitar a los } \\
\text { nuevos } \\
\text { empleados. }\end{array}$ & $\begin{array}{l}\text { La capacitación se hace a los } \\
\text { funcionarios que están dentro } \\
\text { de la institución. No existe } \\
\text { una inducción sobre } \\
\text { temáticas tanto públicas } \\
\text { como de la organización } \\
\text { misma. }\end{array}$ & $\begin{array}{l}\text { La capacitación se } \\
\text { hace a los } \\
\text { funcionarios que } \\
\text { están dentro de la } \\
\text { institución. No existe } \\
\text { una inducción sobre } \\
\text { temáticas tanto } \\
\text { públicas como de la } \\
\text { organización misma. }\end{array}$ & $\begin{array}{l}\text { En ambas instituciones se presenta } \\
\text { que no existe una inducción al } \\
\text { momento de ingresar nuevas } \\
\text { personas a la institución pública. }\end{array}$ \\
\hline $\begin{array}{l}\text { Administrar los } \\
\text { suelos y salario. } \\
\text { (determinar } \\
\text { cómo se } \\
\text { compensará a } \\
\text { los empleados) }\end{array}$ & $\begin{array}{l}\text { Se realiza una nivelación de } \\
\text { remuneración para suplir el } \\
\text { estancamiento de la carrera } \\
\text { funcionaria, en función del } \\
\text { ascenso que no se tan } \\
\text { rápidamente. }\end{array}$ & $\begin{array}{l}\text { Los sueldos son en } \\
\text { función de los } \\
\text { grados y cargo que } \\
\text { tenga dentro de la } \\
\text { institución. }\end{array}$ & $\begin{array}{l}\text { Por una parte, según estancamiento } \\
\text { de la carrera funcionaria la U.V. } \\
\text { aplica una nivelación de } \\
\text { remuneración. Pero, por otra el } \\
\text { Ministerio Mantiene los sueldos de } \\
\text { acuerdo a los grados que se tenga. } \\
\text { Esto en el caso de los funcionarios } \\
\text { de planta, en ambas instituciones en } \\
\text { relación a otros tipos de contrato es } \\
\text { de acuerdo a las estipulaciones en } \\
\text { éste. }\end{array}$ \\
\hline $\begin{array}{l}\text { Brindar } \\
\text { incentivos y } \\
\text { prestaciones. }\end{array}$ & $\begin{array}{l}\text { La administración es más } \\
\text { bien punitiva en sus } \\
\text { ordenanzas. }\end{array}$ & $\begin{array}{l}\text { No existe un } \\
\text { incentivo monetario. }\end{array}$ & $\begin{array}{l}\text { En ambas instituciones se deja de } \\
\text { lado la motivación al funcionario. Es } \\
\text { más bien punitiva, es decir, exige } \\
\text { pero no entrega beneficios desde un } \\
\text { punto de vista monetario. }\end{array}$ \\
\hline $\begin{array}{l}\text { Evaluar el } \\
\text { desempeño. }\end{array}$ & $\begin{array}{l}\text { Académicos: } \\
\text { Se realiza en forma directa } \\
\text { por cada facultad, además de } \\
\text { la evaluación de los alumnos } \\
\text { No académicos: } \\
\text { Anualmente. }\end{array}$ & $\begin{array}{l}\text { Las evaluaciones se } \\
\text { realizan a todos los } \\
\text { funcionarios, } \\
\text { anualmente. }\end{array}$ & $\begin{array}{l}\text { En las instituciones de acuerdo al } \\
\text { Estatuto administrativo, se deben } \\
\text { aplicar anualmente. Esto es asi. } \\
\text { Siendo factor de evaluación para la } \\
\text { renovación o ascenso de cada } \\
\text { funcionario. }\end{array}$ \\
\hline $\begin{array}{l}\text { Capacitar y } \\
\text { desarrollar. }\end{array}$ & $\begin{array}{l}\text { Dentro de la Universidad } \\
\text { existen instancias de } \\
\text { desarrollo. } \\
\text { Académicos: } \\
\text { Las facultas extienden de } \\
\text { acuerdo a las necesidades de } \\
\text { sus académicos, el plan de } \\
\text { capacitación para el año } \\
\text { correspondiente. } \\
\text { No académicos: } \\
\text { De acuerdo al plan anual de } \\
\text { capacitaciones por medio de } \\
\text { un comité bipartito, en función } \\
\text { de la franquicia Sence. }\end{array}$ & $\begin{array}{l}\text { En el ministerio por } \\
\text { medio del Comité } \\
\text { bipartito, se alzan } \\
\text { los planes de } \\
\text { capacitaciones para } \\
\text { las personas, dando } \\
\text { el beneficio respecto } \\
\text { de los recursos que } \\
\text { existan. }\end{array}$ & $\begin{array}{l}\text { En ambas instituciones se realiza } \\
\text { este plan de capacitación, el cual } \\
\text { está integrado en el presupuesto } \\
\text { anual. Y de acuerdo a estos } \\
\text { recursos se prioriza las } \\
\text { capacitaciones existentes y los } \\
\text { beneficiados con ésta. }\end{array}$ \\
\hline
\end{tabular}

Fuente: Elaboración Propia 
Por tanto, respecto de las políticas y las prácticas que se deben aplicar según la teoría, se puede verificar que algunas de ellas se llevan a cabo dentro de las instituciones públicas, estas son los planes de capacitación, evaluación de desempeño los desempeños y reclutamiento siempre en función de las la limitaciones estatutarias que tienen, de acuerdo a los reglamentos, estatuto administrativos y leyes que repercutan en éstas. Ahora bien, las otros conceptos se encuentran presentes, pero claramente en un menor grado. Por lo tanto, se debería mejorar en este aspecto, para obtener mejores beneficios, tanto a nivel de organización como personales.

\section{Tabla 6: Aplicación de Técnicas}

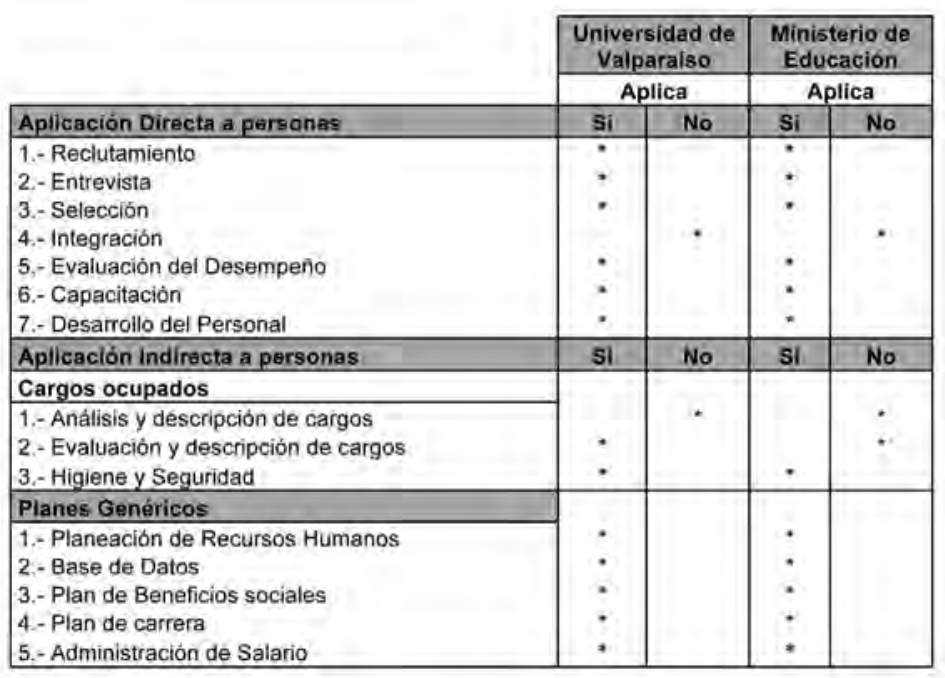

Fuente: Elaboración propia, de acuerdo a análisis de entrevistas.

Según la tabla y de acuerdo a los resultados obtenidos, las instituciones en investigación aplican técnicas en base a las personas que la integran, es decir, funcionarios. Respecto de la aplicación directa, tanto para la Universidad de Valparaíso como para el Ministerio de Educación, podemos ver que la única técnica que no se aplica en ambas es la integración. Esto se relaciona con el compromiso que tienen las instituciones a la hora de mostrar cuando una persona ingresa a la institución, las distintas funciones y normativas a las cuales están sometidas. Esto significa que en las instituciones descritas no existe la etapa denominada inducción.

Existiendo dos tipos de Reclutamiento, el interno El reclutamiento puede ser interno, el cual es aplicado a los candidatos que trabajan en la organización, o bien el externo que se dirige a los candidatos que están en el mercado de recursos humanos.
Tabla 7: Reclutamiento, Universidad de Valparaíso

\begin{tabular}{|l|l|l|l|}
\hline \multicolumn{1}{|c|}{ Categoria } & \multicolumn{1}{|c|}{$\begin{array}{c}\text { Sub- } \\
\text { Categoria }\end{array}$} & $\begin{array}{c}\text { Sub-Sub } \\
\text { Categoria }\end{array}$ & \multicolumn{1}{|c|}{ Frases } \\
\hline $\begin{array}{l}\text { B: } \\
\text { Reclutamiento }\end{array}$ & $\begin{array}{l}\text { B1: } \\
\text { Proceso de } \\
\text { ingreso }\end{array}$ & $\begin{array}{l}\text { B1-2-3:Tipos } \\
\text { de concurso }\end{array}$ & $\begin{array}{l}\text { 3.- Hay que diferenciar, en el caso de los } \\
\text { cargos académicos los concursos son } \\
\text { públicos, no hay concursos internos, } \\
\text { siempre se desarrollan concursos. En el } \\
\text { caso de los funcionarios no académicos y } \\
\text { de orden administrativo, cuando se produce } \\
\text { una vacante nosotros evaluamos si el cargo } \\
\text { que se produce de vacante, es un cargo } \\
\text { que efectivamente supone una condición de } \\
\text { promoción o de ascenso para los } \\
\text { funcionarios digamos que cumplen esa } \\
\text { labor. Si es asi, desarrollamos un concurso } \\
\text { interno, si el concurso interno se declara } \\
\text { desierto, desarrollamos. }\end{array}$ \\
\hline
\end{tabular}

Fuente: Elaboración propia, de acuerdo a análisis de entrevistas.

\section{Tabla 8: Reclutamiento, Universidad de Valparaíso}

\begin{tabular}{|l|l|l|}
\hline \multicolumn{1}{|c|}{ Categoria } & \multicolumn{1}{|c|}{$\begin{array}{c}\text { Sub- } \\
\text { Categoria }\end{array}$} & \multicolumn{1}{c|}{ Frases } \\
\hline $\begin{array}{l}\text { B: } \\
\text { Reciutamiento }\end{array}$ & $\begin{array}{l}\text { B2: } \\
\text { Procedimiento }\end{array}$ & $\begin{array}{l}\text { 1.- El procedimiento contempla que, se reciben los } \\
\text { curriculum y el primer paso es contrastar que todos } \\
\text { quienes han postulado, cumplan con los requisitos } \\
\text { minimos para postular, Ahi ocurre una primera } \\
\text { separación 0 depuración de los curriculum, porque hay } \\
\text { personas que postulan no cumpliendo con los requisitos, } \\
\text { quedando fuera de base. Luego se toman esos } \\
\text { curriculum que califican para el cargo y se les otorga } \\
\text { puntaje. Los mejores puntajes, o los diez con mejores } \\
\text { puntajes habitualmente se les somete a un examen } \\
\text { psicológico, y ese examen emite un informe que } \\
\text { establece una cierta prelación y ese mismo comité es el } \\
\text { que decide que persona se adapta mejor en la } \\
\text { psicológico y en lo laboral al cargo. Entonces. esa } \\
\text { persona gana el concurso }\end{array}$ \\
\hline
\end{tabular}

Fuente: Elaboración propia, de acuerdo a análisis de entrevistas. 
Tabla 9: Reclutamiento, Ministerio de Educación (Regional)

\begin{tabular}{|l|l|l|l|}
\hline \multicolumn{1}{|c|}{ Categoria } & Sub-Categoria & Sub- Sub Categoria & \multicolumn{1}{c|}{ Frases } \\
\hline $\begin{array}{l}\text { B: } \\
\text { Reclutamiento }\end{array}$ & $\begin{array}{l}\text { B1: } \\
\text { Proceso de } \\
\text { ingreso }\end{array}$ & $\begin{array}{l}\text { B1-2-1: } \\
\text { Ingreso por } \\
\text { Concurso público }\end{array}$ & $\begin{array}{l}\text { 1.- El personal de planta de } \\
\text { Carrera son los funcionarios } \\
\text { públicos permanentes del Servicio. } \\
\text { Se ingresa a esta Planta } \\
\text { exclusivamente por concurso } \\
\text { público. }\end{array}$ \\
\hline $\begin{array}{l}\text { B: } \\
\text { Reclutamiento }\end{array}$ & $\begin{array}{l}\text { B1: Proceso de } \\
\text { ingreso }\end{array}$ & $\begin{array}{l}\text { B1-3-2: } \\
\text { Ingreso por } \\
\text { Contrata }\end{array}$ & $\begin{array}{l}\text { 2.- Primero la persona por lo } \\
\text { general entra a contrata y después } \\
\text { postula a la planta y dentro del } \\
\text { escalafón de profesionales tu } \\
\text { entras app en un grado 15 y tiene } \\
\text { un tope de grado 4, }\end{array}$ \\
\hline $\begin{array}{l}\text { B: } \\
\text { Reclutamiento }\end{array}$ & $\begin{array}{l}\text { B1: Proceso de } \\
\text { ingreso }\end{array}$ & $\begin{array}{l}\text { B1-4-1: } \\
\text { Ingreso por } \\
\text { Honorarios }\end{array}$ & $\begin{array}{l}\text { 1.- Este presupuesto incluye } \\
\text { obligatoriamente los recursos } \\
\text { financieros para el pago de las } \\
\text { remuneraciones de la dotación de }\end{array}$ \\
\hline
\end{tabular}

Fuente: Elaboración propia, de acuerdo a análisis de entrevistas.

Tabla 10: Reclutamiento, Ministerio de Educación (Regional)

\begin{tabular}{|c|c|c|c|c|}
\hline Categoría & Sub- Categoria & Frases & $\begin{array}{l}\text { Sub-sub } \\
\text { Categoria }\end{array}$ & Frases \\
\hline $\begin{array}{l}\text { B: } \\
\text { Reclutamiento }\end{array}$ & $\begin{array}{l}\text { B2: } \\
\text { Procedimiento }\end{array}$ & $\begin{array}{l}\text { 1.- Los criterios } \\
\text { utilizados para el } \\
\text { reclutamiento de los } \\
\text { funcionarios se } \\
\text { encuentran normados } \\
\text { en el Estatuto } \\
\text { Administrativo y } \\
\text { cuerpos legales } \\
\text { complementarios y } \\
\text { estos son aplicados } \\
\text { en total concordancia } \\
\text { con la norma. } \\
\text { 3.- Me hace pasar por } \\
\text { un proceso de } \\
\text { entrevista en el que } \\
\text { participa ella, el } \\
\text { asesor juridico y todas } \\
\text { esas cosas, y me } \\
\text { dicen que yo soy la } \\
\text { persona escogida } \\
\text { para el cargo. }\end{array}$ & $\begin{array}{l}\text { B2-1-3: } \\
\text { Término } \\
\text { del } \\
\text { proceso }\end{array}$ & $\begin{array}{l}\text { 3.- una vez que llama } \\
\text { a concurso, no puede } \\
\text { detener el proceso } \\
\text { salvo que pase algo } \\
\text { de fuerza mayor, pero } \\
\text { empezó el proceso, el } \\
\text { llamado y tiene que } \\
\text { terminarlo, teniendo } \\
\text { dos resultados o } \\
\text { nombra a la persona o } \\
\text { lo declara desierto. }\end{array}$ \\
\hline
\end{tabular}

Fuente: Elaboración propia, de acuerdo a análisis de entrevistas.
De acuerdo a lo que plantea Chiavenato, en las instituciones en investigación, existen los siguientes tipos de Reclutamiento.

En la Universidad de Valparaíso, se hace una distinción respecto del funcionario Académico, ya que es reclutado siempre de forma externa el concurso público que se realiza va dirigido a personas externas de la institución.

Por tanto el tipo de reclutamiento es externo.

En el caso de los funcionarios no académicos y funcionarios del Ministerio de Educación, una vez que se abre una vacante, siempre se evalúa la posibilidad de promoción 0 ascenso de sus funcionarios, es decir, se dirige en primer lugar a personas que están dentro de ella, desarrollándose de esta manera un concurso interno. Por tanto, se aplica el tipo de reclutamiento interno.

Ahora bien, tanto el Rector de la Universidad como el Secretario Regiona Ministerial de Educación tienen la facultad de contratar, respecto de sus necesidades en la institución por el solo orden de la ley. Este tipo de reclutamiento, es a través de contratación por contrata y honorarios y es, por tanto, externo, ya que se buscan personas de confianza, pero que están fuera de la institución.

Siguiendo con Alles (2010), plantea que existen supra competencias, las cuales se clasifican en:

1.- Intelectuales, 2.- Interpersonales, 3.- Adaptabilidad, 4.- Orientación a los Resultados

De acuerdo a la sub-categoría, reconocimiento de competencias, establecida en el análisis de los resultados, se puede establecer que las competencias mencionadas, se agrupan como sigue:

\section{1.- Universidad de Valparaíso}

\begin{tabular}{|c|c|}
\hline Número Asignación & Nombre \\
\hline UV1 & Osvaldo Corrales \\
\hline UV2 & Cristián Moyano \\
\hline UV3 & Gonzalo Lira \\
\hline UV4 & René Astudillo \\
\hline
\end{tabular}

2.- Ministerio de Educación (Regional)

\begin{tabular}{|c|c|}
\hline Número Asignación & Nombre \\
\hline MIN1 & Patricia Colarte \\
\hline MIN2 & María Isabel Peña \\
\hline MIN3 & Néstor Vidal \\
& Ronald Pfeng \\
\hline
\end{tabular}


Tabla 10: Reclutamiento, Ministerio de Educación (Regional)

\begin{tabular}{|c|c|c|c|c|}
\hline $\mathbf{N}^{\circ}$ & $\begin{array}{l}\text { Intelectuales } \\
\text { (1) }\end{array}$ & $\begin{array}{l}\text { Interpersonales } \\
\text { (2) }\end{array}$ & $\begin{array}{l}\text { Adaptabilidad } \\
\text { (3) }\end{array}$ & $\begin{array}{l}\text { Orientación a los } \\
\text { Resultados (4) }\end{array}$ \\
\hline UV1 & $\begin{array}{l}\text { - Capacidad directiva } \\
\text { - Capacidad de } \\
\text { comunicación y de } \\
\text { diálogo } \\
\text { - capacidad para } \\
\text { resolver conflictos } \\
\text { - Capacidad de } \\
\text { resolución de } \\
\text { problemas }\end{array}$ & $\begin{array}{l}\text { Capacidad para } \\
\text { organizar }\end{array}$ & $\begin{array}{l}\text { - Trabajar en } \\
\text { equipo }\end{array}$ & $\begin{array}{l}\text { - Persona ordenada } \\
\text { y sistemática en el } \\
\text { manejo de la } \\
\text { documentacion que } \\
\text { a mi me } \\
\text { corresponde } \\
\text { administrar }\end{array}$ \\
\hline UV2 & $\begin{array}{l}\text { - Liderar grupo } \\
\text { - Poner melas }\end{array}$ & $\begin{array}{l}\text { Gestionar en el } \\
\text { cambio }\end{array}$ & $\begin{array}{l}\text { Capacidad de } \\
\text { formar equipos }\end{array}$ & $\begin{array}{l}\text { - Buen grado o } \\
\text { nivel de } \\
\text { frustración }\end{array}$ \\
\hline UV3 & $\begin{array}{l}\text { - Negociación } \\
\text { - Mediación }\end{array}$ & $\begin{array}{l}\text { Trato } \\
\text { interpersonal }\end{array}$ & & \\
\hline UV4 & $\begin{array}{l}\text { - Preparación } \\
\text { académica para } \\
\text { desarrollar un cargo }\end{array}$ & $\begin{array}{l}\text { Asesoria con mi } \\
\text { conocimiento }\end{array}$ & $\begin{array}{l}\text { Prestar con el } \\
\text { ejercicio del } \\
\text { cargo. }\end{array}$ & \\
\hline $\begin{array}{l}\text { MIN } \\
1\end{array}$ & $\begin{array}{l}\text { - Intelectuales } \\
\text { - Organizacionales }\end{array}$ & $\begin{array}{l}\text { Interpersonales } \\
\text { Personales }\end{array}$ & Tecnológicas & \\
\hline $\begin{array}{l}\text { MIN } \\
2\end{array}$ & $\begin{array}{l}\text { - Conocimiento } \\
\text { - Experiencia } \\
\text { - Capacidad de } \\
\text { análisis }\end{array}$ & & Capacitación & \\
\hline $\begin{array}{l}\text { MiN } \\
3\end{array}$ & $\begin{array}{l}\text { - Mente matemática } \\
\text { - Poder liderar al } \\
\text { grupo }\end{array}$ & & $\begin{array}{l}\text { Actitud positiva } \\
\text { ante los } \\
\text { planteamientos }\end{array}$ & $\begin{array}{l}\text { Criterio dado por } \\
\text { años de experiencia }\end{array}$ \\
\hline
\end{tabular}

Fuente: Elaboración Propia

A través del reconocimiento de las competencias por parte de cada funcionario, se logra realizar una clasificación de éstas, en supra competencias. Se puede verificar, que existe un claro conocimiento de lo que son y cuales mantienen. Esto beneficia a los servicios públicos y, en particular, a estas dos instituciones en investigación, ya que con estas competencias se logra tener una visión global de las cosas en todo orden jerárquico, pudiendo así detectar falencias y corregirlas de forma inmediata.
De acuerdo a Simon L Dolan, 2003, la gestión por competencias crece en importancia en el mundo empresarial, su aplicación ofrece novedad de un estilo de dirección en que prima el factor humano, en el que cada persona, empezando por los propios directivos, debe aportar sus mejores cualidades profesionales a la empresa.

En ambas instituciones, la gran mayoría de las respuestas fueron que no existía una buena gestión de las competencias de cada uno de sus funcionarios. Que es un punto en el cual están al debe y que se debería mejorar.

De acuerdo a los artículos del DFL $N^{\circ} 29$ y a las respuestas de ambas instituciones, se verifica la aplicación de la ley en la respecto de los procedimientos de capacitación, de las calificaciones, del ingreso y de la carrera funcionaria. 


\section{CONCLUSIONES}

La Universidad es un tipo de servicio público atípico dentro de los demás servicios. Si bien está regida por normativas públicas, estás mismas le otorgan la facultad para tener su propio estatuto dándole con esto una autonomía académica, económica y administrativa.

Desde el punto de vista de la administración de personal, consta con diez facultades, con cuarenta y tres carreras, por tanto tiene una dotación aproximadamente entre cargos de planta, contrata y honorarios de tres mil ciento setenta y tres personas. La institución tiene dos tipos de funcionarios, funcionarios académicos y no académicos. Al ser una institución pública sus funcionarios no académicos están regidos por el Estatuto Administrativo, quedando afecto a todo tipo actualizaciones y leyes que repercutan en éste.

Todos los funcionarios están constantemente en perfeccionamiento, teniendo instancias de desarrollo de sus capacidades, por medio de un plan de capacitación. Esta capacitación se realiza de acuerdo a las necesidades que cada facultad tenga respecto de sus funcionarios académicos, mientras que para los no académicos es a través de un comité bipartito quien eleva una solicitud anual articulado en torno a la franquicia Sence.

También existe una instancia de evaluación del desempeño, que se hace por medio de evaluaciones anuales, siendo todos los funcionarios evaluados. Se verifica en relación a los funcionarios no académicos el cumplimiento respecto de los factores y subfactores que establece el Estatuto Administrativo cumpliendo con las precalificaciones, para así tener una calificación final. En el caso de los académicos, cada facultad tiene un comité de evaluación siendo ellos quienes califican. Además se realiza una evaluación desde el punto de vista del alumnado respecto de aquel docente o funcionario académico. Esto con la finalidad de calificar también en función de los desempeños en el aula.

Para ingresar a la Universidad el proceso de reclutamiento de los funcionarios, se hace a través de concursos públicos, contratación a nivel de confianza, nivel de contrata y honorarios. Los llamados se realizan por medio de las publicaciones en el diario 0 en la página web de la institución. En ese proceso, se exponen qué cargos están vacantes, a qué se postula y cuáles son los requisitos. Pero, no existe una descripción del cargo 0 de función específica, respecto de las competencias necesarias para éste.
Esta no especificación de las competencias laborales, no existe ya que no hay un modelo de competencias. En relación a los funcionarios no académicos, solo existe una descripción de cargos en función de lo que estipula el Estatuto para obtener un grado $\mathrm{u} / \mathrm{o}$ a nivel de concursos. Respecto de los académicos se está avanzando en un manual de descripción de perfiles, ya que tampoco existe una especificación de lo que cada cargo en los distintos estamentos debe realizar.

Existe un claro concepto por parte de quienes integran la institución de lo que significa las competencias laborales de manera que logran definirlas y a la vez reconocer cuales poseen. Dejando en claro que debieses existir una mejora en esta temática.

Los funcionarios no académicos que optan a una planta comienzan lo que es llamado como carrera funcionaria, al día de hoy esto no se aplica en la universidad. No se aplica, no porque no exista sino porque no hay cupos o vacantes vigentes. Es por esto que en la universidad, se realizó una nivelación de grado, que busca el ascenso desde el punto remuneracional. Con esto equipara de cierta manera el estancamiento de la carrera funcionaria con la obtención del grado.

El Ministerio de Educación es un servicio público el cual tiene por objeto aplicar y fiscalizar el cumplimiento de las normativas educacionales. En la quinta región existe una secretaría Ministerial de Educación quien es mediador y fiscalizador entre las instituciones de Educación tanto superior como Media Básica y pre-escolar.

Desde el punto de vista de la administración de personal, tiene una dotación aproximadamente entre cargos de planta, contrata y honorarios de dos mil en la Quinta Región.

Al igual que la Universidad de Valparaíso, los funcionarios están constantemente en perfeccionamiento, teniendo instancias de desarrollo de sus capacidades, por medio de un plan de capacitación. Esta capacitación se realiza a través de un comité bipartito quien eleva una solicitud anual.

También existe una instancia de evaluación del desempeño que se hace por medio de evaluaciones anuales, siendo todos los funcionarios evaluados. Se verifica en relación a los funcionarios el cumplimiento respecto de los factores y subfactores que establece el Estatuto Administrativo cumpliendo con las precalificaciones, para así tener una calificación final.

Para ingresar al ministerio el proceso de reclutamiento de los funcionarios, se hace a través de concursos públicos, 
contratación a nivel de confianza, nivel de contrata y honorarios. Los llamados se realizan por medio de las publicaciones en el diario 0 en la página web de la institución. En ese proceso, se exponen qué cargos están vacantes, a qué se postula y cuáles son los requisitos. Pero, no existe una descripción del cargo 0 de función específica, respecto de las competencias necesarias para éste.

En relación a la definición de cargos, existe solo una descripción de cargos en función de lo que estipula el Estatuto para obtener un grado $\mathrm{u} / \mathrm{o}$ a nivel de concursos.

Existe un claro concepto por parte de quienes integran la institución de lo que significa las competencias laborales, de manera que logran definirlas y a la vez reconocer cuales poseen. Dejando en claro que debieses existir una mejora en esta temática.

Los funcionarios al ingresar comienzan lo que es llamado como carrera funcionaria, al día de hoy esto no se aplica en la universidad. No se aplica, no porque no exista sino porque no hay cupos 0 vacantes vigentes.

Dicho esto y de acuerdo a los objetivos planteados podemos decir que la determinación de las competencias se logra respecto de la evaluación que hacen los mismos trabajadores 0 funcionarios pero no existe una estipulación por cada cargo. Y cuando se llama a concurso aparece una descripción pero solo de los requisitos que debe cumplir cada postulante.

Como queda plasmado en la Investigación, el reclutamiento se realiza a través de concursos públicos y concursos internos. Teniendo como fuentes en el caso de la Universidad sus propios alumnos, además de otros postulantes. Y para el Ministerio Personas de otro servicio público o de otra calidad de postulante. Estos concursos para el son a nivel central. También existe otra instancia de reclutamiento quien lo hace los jefes superiores de cada institución por la facultad que les otorga la ley, y esto hace que ingresen personas por contrata u honorarios.

En ambas instituciones, la carrera funcionaria está en un estado de congelamiento. Al no existir vacantes, no se le da paso a que personas de la institución puedan optar a nuevos grados lo que les significará también un beneficio monetario. Una de las debilidades de la carrera funcionaria es esa, que mantiene a personas por muchos años lo cual no da cabida a nuevas experiencias y conocimiento y a la vez trunca la posibilidad de surgir de otro funcionario y el ingreso de otra persona. Es por esto que hoy en día a nivel de servicio público se está dando mucho el tipo de contratación a contrata, lo que de cierta manera existe una inestabilidad laboral para quienes al treinta y uno de Diciembre deben renovar, y esto será en función de las evaluaciones de desempeños y del cumplimiento de metas que haya tenido.

Por tanto, a través del contraste que se hizo de las competencias laborales, el reclutamiento y la carrera funcionaria se puede concluir globalmente que se debe hacer urgentemente un cambio en el Estatuto Administrativo, modificarlo de manera tal que los ascensos sean más rápidos, que las calificaciones sean especificas al trabajo realizado, que las capacitaciones sean para todos los funcionarios y también en temáticas que le sirvan para una futura postulación y finalmente que las Universidades estatales logren tener una mayor autonomía de la que tienen, en sus procesos administrativos como económicos. 


\section{BIBLIOGRAFÍA}

-1 Alles, M., 2010. Gestión por Competencia. Nueva Edición ed. s.l.:Granica.

-2 Chiavenato, I., 2004. Administración de Recursos Humanos. Quinta ed. Bogotá, Colombia: Mc Graw Hill.

-3 Chiavenato, I., 2004. Gestión del Talento Humano. Bogotá, Colombia: Mc Graw Hill.

-4 Dessler, G., 2001. Administración de Personal. Octava ed. México: Pearson Educación.

- 5 Decreto fuerza de Ley № 147, 1981. Estatuto Universidad de Valparaíso.

-6 Dolan, S.I., Valle, R., Jackson, S.E. \& Schuler, R.S., 2003. La Gestión de los Recursos Humanos. s.I.:Mc Graw Hill.

-7 Educación, M.d., 2012. DFL № 4. s.l.:s.n

-8 Hacienda, M.d., 2004. DFL $N^{\circ} 29$. s.l.:s.n.

-9 Interior, M.d. \& Administrativa, S.d.D.R.y., 1998. Decreto 1825. s.l.:s.n.

-10 Levy-Leboyer, C., 1997. Gestión de las Competencias. s.l.:Gestión 2000.

-11 Ley No18.834, 1989. Estatuto Administrativo

-12 López, J.F., 2004. Gestión por Competencias. s.l.:Pearson Educación.

-13 Mertens, L., 2000. La Gestión por Competencia Laboral en la empresa y la formación Profesional. s.l.:s.n.

-14 S.L, P.V., 2008. Selección del personal. España: Editorial Vértice.

-15 Simon L Dolan, R.V.C.S.E.J.R.S., 2007. La Gestión de los Recursos Humanos. s.I.:Mc Graw Hill.

- $\quad$ www.ben.cl

- www.martaalles.com

- $\quad$ www.mieduc.cl

- www.scielo.cl
DISCURSO EN CEREMONIA DEL LANZAMIENTO DE LA REVISTA DE INVESTIGACIÓN APLICADA EN CIENCIAS EMPRESARIALES.

Prof. Dr. Siegfried Muñoz Van Lamoen

Se me ha solicitado expresar algunas palabras, en relación con la investigación científica, como una de las actividades inherentes e irrenunciables del quehacer académico universitario. Hoy, que nos hemos reunido para desarrollar esta actividad académica, el "lanzamiento de la Revista de Investigación aplicada en Ciencias Empresariales", de la Escuela de Auditoría, siento que debería ser habitual la celebración de foros, reuniones y congresos, que permitan la difusión, la reflexión y el intercambio de experiencias, en el campo propio del área diferenciada del conocimiento, que cultivamos.

Me solazo, pues, de esta instancia que propicia la investigación y la difusión de los resultados científicos. Al respecto, quisiera iniciar el tema, explayándome en el ámbito de la teoría de la ciencia o epistemología científica, a través del análisis del concepto de Ley que, si lo definimos como la determinación o establecimiento de relaciones constantes, comprobadas entre fenómenos, cabría preguntarse; ¿ Cómo se explica, entonces, que si se ha definido de este modo, la Ley se muestre, luego, andando el tiempo, como falsa 0 meramente aproximada 0 que sea sustituida por conceptos antagónicos, no obstante que se ha hablado de comprobación.

Respecto al carácter contradictorio de la definición, de un aspecto tan fundamental de la ciencia, como lo es la noción de Ley, cabe señalar que el hecho más interesante, con respecto a las leyes de la naturaleza es que se sabe que, virtualmente, todas ellas están equivocadas y las pocas excepciones existentes, parece que con toda probabilidad dejarán de serlo dentro de poco.

Como corolario de lo que acabamos de considerar, surge la idea de que el concepto que discutimos es de naturaleza tal, que por el momento es imposible alcanzar una definición rígida y acotada. La historia de la ciencia nos muestra, en efecto, que las leyes y principios científicos se encuentran en un proceso de rectificación constante. No es como se creyó en una época, principios absolutos, inmutables.

Otro elemento conceptual relevante, en el análisis que presentamos, es el de la observación y su relación con el problema de la objetividad. Si la objetividad se analiza bajo el siguiente lema: "la escala de observación crea el fenómeno", ¿ significa esto introducir un elemento subjetivo en la observación?. No, esto significa que ciertos principios se verifican solo dentro de ciertos límites de observación o condiciones experimentales.

De este mismo hecho, podemos inferir una de las características más salientes de la ciencia en su devenir histórico. Una teoría nueva o un 
nuevo conjunto de leyes, nunca deroga del todo las adquisiciones precedentes, es más, la valorización de éstas en la nueva construcción puede adoptar la forma de una aproximación vinculada a una cierta escala de observación.

Finalmente en este punto, refiriéndonos a la relación entre la teoría y la observación, digamos con Einstein, que no hay observación sin teoría. La observación empírica pre-teorética, sin hipótesis de trabajo, está condenada al fracaso.

En otro orden de ideas, me referiré al problema de la clasificación de las ciencias. Piaget, indica que no sería posible mantener ninguna distinción de naturaleza entre lo que se denomina a menudo 'ciencias sociales' y las llamadas 'ciencias humanas', ya que es evidente que los fenómenos sociales dependen de todos los caracteres del hombre, incluidos los procesos psicofisiológicos, y que, recíprocamente, las ciencias humanas son todas ellas sociales, en alguno de sus aspectos. La distinción no tendría sentido (y es ésta la hipótesis que se toma como punto de partida), si no se sabe que se podría disociar, lo que compete a las sociedades particulares en las que vive y lo que constituye la naturaleza humana universal. Prefiere llamarlas 'ciencias del hombre'.

Independiente de los conceptos piageteanos, considero oportuno introducir en esta ponencia discursiva, otra clasificación de las ciencias establecida en el amplio conjunto de disciplinas que conciernen a las múltiples actividades de hombre. Esta clasificación separa, claramente, las ciencias nomotéticas, que se proponen formular 0 buscar leyes y las ciencias históricas, jurídicas y filosóficas. Entre ellas, la diferencia cualitativa es que unas se ocupan de reflexionar, continuada 0 episódicamente y las otras, que difieren profundamente, pues deben constituirse en una ciencia propiamente tal, con inventario y delimitación de problemas y con determinación y perfeccionamiento de métodos. Para una mayor y más precisa comprensión, hemos de decir : una cosa es el razonamiento y otra los procedimientos de observación y sobretodo de verificación.

Según Bunge, las ciencias se han de dividir en formales (0 ideales) y fácticas (o materiales). Esta separación considera el objeto o tema de las respectivas disciplinas, así como los enunciados que se proponen establecer. Mientras los enunciados formales consisten en relaciones entre signos, los enunciados de las ciencias fácticas se refieren, en su mayoría, a entes extracientíficos: a sucesos y a procesos.

La división de Bunge tiene en cuenta el método por el cual se ponen a prueba los enunciados verificables: mientras las ciencias formales se contentan con la lógica para demostrar rigurosamente sus teoremas (los que, sin embargo, pudieron haber sido adivinados por inducción común o de otras maneras), las ciencias fácticas necesitan más que la lógica formal: para confirmar sus conjeturas necesitan de la observación $\mathrm{y} / 0$ el experimento.
Las teorías matemáticas abstractas, esto es, que contienen términos no interpretados (signos a los que no se atribuye un significado fijo, y que por lo tanto, pueden adquirir distintos significados) pueden desarrollarse sin poner atención al problema de la verdad. En las ciencias fácticas, la situación es enteramente diferente. Ellas no emplean símbolos vacíos (variables lógicas), sino tan solo símbolos interpretados. También consideran la racionalidad, esto es, la coherencia con un sistema de ideas aceptado previamente; ésta es necesaria, pero no suficiente para los enunciados fácticos; además, se ha de exigir de los enunciados de las ciencias fácticas, que sean verificables en la experiencia, sea indirectamente (en el caso de las hipótesis generales), sea directamente (en el caso de las consecuencias singulares de las hipótesis). Únicamente, después de que haya pasado las pruebas de la verificación empírica, podrá considerarse que un enunciado es adecuado a su objeto, o sea, que es verdadero y, aún así, hasta nuevo aviso. Por esto es que el conocimiento fáctico verificable, se llama a menudo, ciencia empírica.

Las ciencias formales, demuestran 0 prueban; las ciencias fácticas verifican (confirman o desconforman) hipótesis que en su mayoría son provisionales.

Desde la década del 50 del siglo pasado, se produjo un giro copernicano en las formas de hacer ciencia. Hubo, desde esa época, el reemplazo de una concepción de la ciencia, en general, por otra diferente e inclusive opuesta. La discrepancia es radical y no permitió siquiera una reacción contraria del paradigma epistemológico anterior. Hasta ese entonces no se había producido un cambio tan sustancial como irremediable en el estilo de hacer ciencia. Desde el concepto de ciencia empírica solo realizable a través de la observación y la medición y cuyo método inductivo era el único apropiado para obtener resultados verdaderos como un método que no permitía la obtención de principios generales, simples y seguros para la explicación y predicción de fenómenos observables, por el solo hecho de resumir y generalizar inductivamente los datos del corpus, a un estilo, cuyo procedimiento hipotéticodeductivo-observacional, ya aplicado en las áreas más avanzadas de la ciencia empírica. En el modelo hipotético deductivo, el científico inventa, gracias a su conocimiento, un conjunto de conceptos -construcciones teóricas-, un sistema de hipótesis formuladas a través de estas conceptualizaciones y una interpretación de la teoría resultante. Todo ello, para permitir establecer conexiones explicativas y predictivas, entre los datos de la observación directa.

Como se sabe, toda teoría debe interesarse en las propiedades de la teoría como tal y en tener un poder explicativo y predictivo respecto de su objeto.

Ahora bien, el principio básico de que la ciencia no está hecha, sino que está siempre haciéndose, en la perspectiva de la Filosofía de la Ciencia el haber alcanzado la etapa explicativa, a partir de la formulación de 
modelos hipotéticos deductivos, que significó un cambio relevante, postempirista, en la forma de hacer ciencia, no se transforma en el desideratum en las disciplinas de cualquier área diferenciada del conocimiento que se cultive, pues muchas de ellas están recibiendo contraejemplos, que son preguntas que se le formulan y que los paradigmas, en el sentido Kuhneano, vigentes no pueden responder, pues el alcance y profundidad de éstos no les permite dar cuenta de todos los problemas planteados. Por lo expresado, creo, firmemente, que en el campo de la Filosofía de la ciencia se está incubando un nuevo paradigma para las Ciencias Sociales, que parte distinguiendo sobre la base del objeto de estudio y del método, entre ciencias naturales y sociales, deslindando el objeto para las ciencias sociales al mundo histórico propio del ámbito de la acción humana y en el campo metodológico el interés, en las ciencias sociales, se centraría en comprender el caso individual, sin remitirlo a una ley universal que, al englobarlo, lo explique. Así, las ciencias sociales están interesadas tanto en explicar como en comprender el mundo social.

En el campo específico de las ciencias empresariales, debemos expresar que éstas pertenecen al ámbito de la Administración y ésta es una ciencia social, factual o humana, por tanto, lo explicado precedentemente, relativo a las ciencias sociales incumbe absolutamente a las ciencias empresariales.

Por ello, ser científicos en el estudio de la administración implica conocer por medio de sus causas o principios las propiedades de la organización y de los fenómenos que ocurren en ella. Además, significa hacerlo de modo metódico, aplicando el rigor en la búsqueda de las causas. Podemos, entonces, ser científicos si delimitamos bien el objeto de estudio y le aplicamos un método adecuado. Ppor un lado, buscamos mantenernos cerca de los fenómenos; pero, por otro, (como queremos ser científicos), buscamos objetividad y nos alejamos de ellos (...) ¿cómo lograr ambos fines?, bajando al campo, hablando con la gente de la organización estudiada, operacionalizando variables, triangulando respuestas de distintos entrevistados, buscando modelos causales, eliminando conjeturas poco probables, es decir, realizando casos.

Un estudio de casos, lo hemos de concebir como: el estudio de la particularidad y de la complejidad de un caso singular, para llegar a comprender su actividad en circunstancias importantes y si a esto le añadimos que estudiar un caso obedece al interés del investigador de interiorizarse en los detalles que ofrece el caso en la interacción con los contextos con los cuales se relaciona habitualmente, de modo que, el caso se justifique por su capacidad de proporcionar oportunidades de descubrir nuevas relaciones y conceptos.

Finalmente, quisiera expresar algunos mensajes que se desprenden del hecho que hoy nos convoca. El lanzamiento de la primera revista de la Carrera de Auditoría, constituida por artículos, cuyo origen emana de
Ios resultados de investigaciones cuyo propósito era la Tesis de Grado, de estudiantes de nuestra Escuela. Este hecho físico, material, tangible, contiene dos mensajes: por una parte, nos hace sentido el saber que se puede, que todos podemos, por tanto es un aliciente y una motivación para cada uno de nosotros, el investigar; por otra, ha de significar para nuestras autoridades, que han apoyado decididamente esta actividad académica que ve sus frutos, una vigorización de sus apoyos, de modo tal que permita mejorar las condiciones necesarias para el fomento de la investigación en nuestra Escuela, así como la difusión o divulgación de la ciencia. A este respecto, uno de los fenómenos observados y que no quisiéramos que se diera en nuestra Escuela, es que una parte importante de las publicaciones periódicas en las que se han difundido los trabajos científicos, han dejado de publicarse 0 presentan un carácter irregular, en cuanto a su frecuencia de aparición.

Por lo expresado, invito a la comunidad de la Escuela a incursionar, a nóveles y experimentados, en el hermoso y apasionante campo de la investigación científica.

Dr. Siegfried Muñoz van Lamoen

Prof. Escuela de Auditoría 